\title{
Determinants of postnatal care utilization in Ethiopia: a multilevel analysis
}

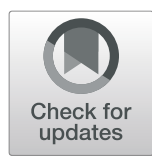

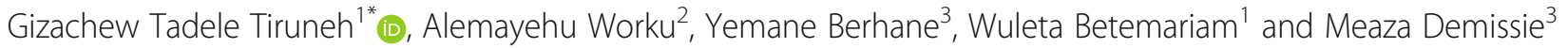

\begin{abstract}
Background: The expansion of primary health care services in Ethiopia made basic health services available and accessible. The Last Ten Kilometers (L1OK) project has strengthened the primary health care system through implementing innovative strategies to engage local communities to improve maternal and newborn health care behavior and practices in Amhara, Oromia, Southern Nations, Nationalities and Peoples [SNNP], and Tigray regions over a decade. Despite the efforts of the government and its partners to improve the use of maternal health services, the coverage of postnatal care is persistently low in the country. This study examined the individual and community level determinants for the persistently low uptake of postnatal care in the project areas.

Methods: The study used a cross-sectional population-based survey that measured maternal and newborn health care practices among women who had live births in the last 12 months preceding the survey in Amhara, Oromia, SNNP, and Tigray regions. Multilevel random effects binary logistic regression analysis was used to assess the independent effects of community-and individual-level factors and moderating effects on the uptake of postnatal care.

Results: This study identified region of residence, obstetric factors, and health service-related factors to be significant determinants for use of postnatal care. Obstetric factors include knowledge of obstetric danger signs (AOR: 1.30; 95\% Cl: 1.05-1.60), cesarean section mode of delivery (AOR: 1.96; 95\% Cl: 1.28-3.00), and institutional delivery (AOR: 10.29; 95\% Cl: 7.57-13.98). While the health service-related factors include attended family conversation during pregnancy (AOR: 1.48; 95\% Cl: 1.04-2.12), birth notification (AOR: 2.66; 95\% Cl: 2.15-3.29), home visits by community health workers (AOR: $1.98 ; 95 \% \mathrm{Cl}$ : 1.58-2.50), and being recognized as a model family (AOR: 1.27; 95\% Cl: 1.03-1.57).

Conclusion: This study demonstrated that community-level interactions and promotive health services including antepartum home visits by community health workers, family conversation, birth notification, and model family, are important determinants to seek postnatal care. The findings also highlight the need for expansion of health facilities or design appropriate strategies to reach the disadvantaged communities. Program managers are recommended to strengthen community-based interventions to improve postnatal care utilization.
\end{abstract}

Keywords: Determinants, Ethiopia, Maternal health service, Postnatal care, Use of health service

\footnotetext{
*Correspondence: gizt121@gmail.com

'The Last Ten Kilometers (L10K) Project, JSI Research \& Training Institute, Inc, Addis Ababa, Ethiopia

Full list of author information is available at the end of the article
}

(c) The Author(s). 2020 Open Access This article is licensed under a Creative Commons Attribution 4.0 International License, which permits use, sharing, adaptation, distribution and reproduction in any medium or format, as long as you give appropriate credit to the original author(s) and the source, provide a link to the Creative Commons licence, and indicate if changes were made. The images or other third party material in this article are included in the article's Creative Commons licence, unless indicated otherwise in a credit line to the material. If material is not included in the article's Creative Commons licence and your intended use is not permitted by statutory regulation or exceeds the permitted use, you will need to obtain permission directly from the copyright holder. To view a copy of this licence, visit http://creativecommons.org/licenses/by/4.0/ The Creative Commons Public Domain Dedication waiver (http://creativecommons.org/publicdomain/zero/1.0/) applies to the data made available in this article, unless otherwise stated in a credit line to the data. 


\section{Background}

Most maternal and newborn deaths are largely preventable or treatable if skilled health care is provided during the intrapartum and early postnatal periods [1]. During the immediate postpartum period, critical interventions to end preventable maternal and newborn deaths need to be delivered [2]. However, in most developing countries, postnatal care (PNC) is the least prioritized program component of maternal and child survival interventions which is illustrated by a high rate of underutilization and discontinuity of maternal and child health programs [3]. Likewise, postnatal care has been poorly implemented in Ethiopia [4]. Despite the efforts of the government and its partners to improve the use of maternal health services through expansion of primary health care, except user free of maternal health services, strengthening the community health system to provide postpartum home visits, only $17 \%$ of women received PNC during the critical period of the first 2 days after delivery; and only $1 \%$ was visited by health extension workers, frontline community health workers. Less than $2 \%$ who delivered outside of the facility and $42 \%$ who delivered at health facility received PNC within 2 days. To make matters worse, of those who delivered in the facility, most did not receive proper PNC. More than two-thirds (69\%) of women who had vaginal birth at the facility were discharged within 24-h after birth and commonly discharged within $6 \mathrm{~h}$ of delivery [5].

Evidence shows that the use of maternal and newborn health services during the postpartum period is influenced by many of socio-demographic, health servicerelated, and cultural factors [6-9]. Multiple studies find parity, mother's education, and a woman's economic status are significant predictors for the utilization of maternity care [10,11]. Researchers also indicate that PNC utilization is affected by distance to facilities, area of residence, place and type of delivery [12-14], experience of problems during delivery, awareness about obstetric related danger signs, and awareness about PNC services [7, 9, 11]. Likewise, the use of antennal care (ANC), skilled attendance during childbirth, quality of ANC, and awareness of danger signs during ANC and delivery are found to be associated with seeking PNC service $[15,16]$.

Cultural beliefs regarding maternal health and illness are also other factors that can prevent women from utilizing modern maternal health care. The traditional postnatal confinement, and certain community rituals that take place during this period, hinder mothers from going to health facilities for PNC service [17].

Compared to antenatal care and skilled attendance at birth, research on postnatal care is limited in developing countries [18]. Moreover, most studies have largely ignored the potential effects of community-level factors that do not show a complete picture of the evaluation of the determinants affecting PNC utilization [19]. As such, this study intends to examine determining factors at individual and community-levels of the persistently low utilization of postnatal health services in Ethiopia.

\section{Methods \\ Context}

Ethiopia has expanded primary health care services through expansion of the Health Extension Program (HEP) and expansion of health centers and promotion of early healthcare-seeking through community mobilization to reach most communities and households and provide preventive, promotive, and basic curative services. The promise of the HEP has been the graduation of model families where health extension workers (HEWs) train households to acquire the necessary knowledge, skills, and behavior change in health practices. When these households demonstrate practical changes in the use of health service programs: environmental health, personal hygiene, and serve as models in their community, then they graduate. To reach more communities, this strategy has been accelerated through the participatory engagement of model families that are early adopters of desirable health practices and have acceptance and credibility by their community and the women development army (WDA) group. The WDA network builds on the critical mass of model families and creates volunteer leaders that scale-up the dissemination of knowledge, innovation, and service utilization through social networks. They are actively engaged in promotion and prevention activities as well as social mobilization efforts to expand HEP deeper into communities and families and ensure community ownership [20].

The Last Ten Kilometers (L10K) project has been supporting in strengthening the HEP through the implementation of innovative strategies to engage local communities to improve high-impact reproductive, maternal, newborn and child health ( $\mathrm{RMNCH}$ ) care behavior and practices in 115 woredas (i.e., districts) in four of the most populous regions of Ethiopia (i.e., Amhara, Oromia, Southern Nations, Nationalities and Peoples [SNNP], and Tigray) since 2008. During the first funding cycle, i.e., between 2008 and 2015, the Project implemented innovative strategies to engage local communities to reach its objectives. Three community-based strategies-Community-Based Data for Decision-Making (CBDDM), family conversation, and birth notificationwere implemented in the 115 woredas covering about 3070 kebeles, the lowest administrative unit.

Community-based data for decision-making, introduced in July 2013, was used to identify pregnant women and to ensure they received antenatal, intrapartum, and postpartum care [21]. CBDDM fostered the 
kebeles to generate and use data to improve maternal and newborn health practices. The strategy identified underserved households and linked them with HEWs and kebele managers helping to address barriers in accessing maternal and newborn health services. Accordingly, HEWs were trained to support WDA team leaders to map 30 households in their catchment areas, to keep each household under surveillance, and to ensure the provision of maternal and newborn health services along the continuum of care. The surveillance system used images so that they could be maintained and updated by individuals with little or no education. HEWs collect data from WDA team leaders' surveillance to help kebele leaders to identify and address barriers that make access to maternal and newborn health services difficult.

The CBDDM strategy has resulted in improvements in institutional deliveries and newborn health care behaviors and practices. However, there was no evidence of any effect of the intervention on postnatal care within 2 days of childbirth [21]. Accordingly, alternative strategies, complementary to CBDDM, such as family conversation and birth notification, were designed to promote maternal and newborn health behaviors. Family conversation, on the other hand, is a forum conducted at the house of a pregnant woman with her family members and relatives who are expected to support her during her pregnancy, labor, delivery, and postpartum period. Family conversation session was introduced early in 2014 to promote birth preparedness and the use of early postpartum care and essential newborn care. Birth notification strategy was introduced by mid-2014 to promote early postnatal care. Since October 2015, L10K focused on institutionalizing the CBDDM strategy and strengthen the implementation of family conversations and birth notification strategies in the 115 woredas [21]. During the intervention period, L10K Project's contribution has shown an increase in skilled delivery from 10 to 67\% between 2011 and 2017. Nevertheless, despite the efforts and huge investments made to improve the use of maternal health services, only one-third of mothers received PNC within $48 \mathrm{~h}$ [22].

\section{Design}

This study used a cross-sectional population-based design. The study population consists of women who had live births in the last 12 months preceding the survey.

\section{Sample size and sampling}

We used the data that was collected from the representative sample of 2724 women aged 15 to 49 years, from 298 Kebeles. The data were drawn from a crosssectional household survey datasets representing the 115 woredas (where L10K operates) and were collected from October-November 2017. The survey employed a twostage stratified cluster sampling method. The details of the design are described somewhere else [23].

The adequacy of the sample size, required to address this study's objective, was checked using StatCalc for a double population formula for comparative crosssectional study design considering different exposure variables including birth order, place of delivery, maternal education, and wealth quintile from the 2016 EDHS report [5]. The assumption made to calculate sample size was considering a $95 \%$ confidence level $(Z \alpha / 2=$ $1.96)$, and design effect $(D=2)$, power of $80 \%$. Based on Anderson's health-seeking behavior model [24], the researchers assumed first birth order, home delivery, no maternal education, and poorest wealth quintile as exposure and highest birth order/6+, facility delivery, higher education, and richest wealth quintile as nonexposure. Adding a $10 \%$ non-response rate, the maximum sample size obtained by birth order was 750 . Accordingly, we ensured that the available sample was adequate to address this objective.

\section{Data collection}

Data were collected through interviews of eligible mothers aged 15-49 years. During the interview, information about household and socio-demographic characteristics of mothers, awareness, and experiences related to the women's use of maternal health services, was collected from women with children in their first year of life. The data were collected using a structured interview questionnaire (Additional file 1) and archived using a web-based mHealth platform (i.e., SurveyCTO) using smartphones.

\section{Measurement}

The outcome variable of interest was, the proportion of women and their newborns who received postpartum care at the health facility or their home within 6 weeks of delivery. It is measured interview of women weather pre-discharge care provided for them and their newborns after 24-h of stay for whom delivered at the health facility and any postnatal check-up for mother's and newborn's health by a health care provider within 6 weeks of giving birth.

The independent variables considered include individual and community level factors. The individual sociodemographic variables include maternal education, husband's education, religion, marital status, household wealth index, and distance to health facility. Obstetric characteristics include mode of delivery, place of delivery, utilization of ANC services, knowledge of obstetric danger signs, and encountered obstetric complications (during pregnancy, childbirth, or postpartum), as well as 
program characteristics including community health workers (CHWs) home visit, model family, and birth notification, were considered. Administrative region and area of residence (clusters/kebeles) were considered as community-level random components.

Model families are defined as those households who received training from HEWs, acquire the necessary knowledge, skills, and behavior in health practices and demonstrate practical changes in the use of health service programs and serve as models in their community. Family conversation is a forum conducted at the house of a pregnant woman with her family members and relatives who are expected to support her during pregnancy, labor, delivery, and the postpartum period. It creates an opportunity to discuss issues such as birth preparedness and essential newborn practices with all these family members together. It is measured by asking women regarding their attendance of at least one family conversations at home during their last pregnancy. While birth notification is a strategy introduced to promote early postnatal care. It is measured through interviews of women weather they took measures to inform the HEW about their childbirth immediately after delivery or not.

A wealth index score was constructed for each household with the principal component analysis of the household's possessions (electricity, watch, radio, television, mobile phone, telephone, refrigerator, table, chair, bed, electric stove, and kerosene lamp), and household characteristics (type of latrine, water source, floor, and wall material). Subsequently, households were ranked according to wealth score and then divided into five quintiles using Principal Component Analysis (PCA) method.

\section{Data analysis}

\section{Individual-level analysis}

Data were analyzed for both descriptive and inferential statistics using Stata version 15.1. Socio-demographic data were summarized by frequency tables and summary statistics. The researcher conducted an individual-level analysis to assess the association between the individual and contextual characteristics of the respondents with PNC use using Pearson's Chi-squared statistics taking the complex survey nature into account.

Post-stratification sampling weights were used to adjust the non-proportional allocation of the sample to the different regions and weighted analysis was used to ensure the representativeness of the survey estimates.

\section{Model specification and assumptions}

Multilevel bivariate and multivariable analysis using cluster-level random effects logistic regression models were used to assess the independent effects of community factors and moderating effects on the association between individual variables and PNC. The models were adjusted for survey design and individual and contextual characteristics of the respondents. To assess the contribution of the respondents' characteristics to the model, a two-level logistic regression model was applied (i.e., individuals (level 1) were nested within communities (level 2).

In fitting models, iterative based backward elimination and forward selection methods were used to select explanatory variables. For the purpose, the independent variables were retained in each of the models if the $p$ value was less than 0.2. Accordingly, maternal education, household wealth index, distance to health facility, family currently recognized as model, family conversations during pregnancy, knew at least 3 obstetric danger signs, encountered obstetric complications, CHW (either by HEWs or WDAs) home visit during pregnancy, ANC visit, place of delivery, mode of delivery, and birth notification, were retained in the model.

\section{Multilevel analysis}

Both random-intercept and random coefficient logistic models were fitted to estimate associations between the individual and community variables and the likelihood of receiving PNC using xtlogit and xtmelogit Stata commands. The null model is fitted without the explanatory variable. The random-intercept logistic models were fitted to assess the influence of unobserved communitylevel characteristics on the overall variation in PNC utilization allowing the probability of receiving PNC to vary randomly across communities assuming the effects of individual characteristics are the same in each community, i.e. the coefficients of all explanatory variables are fixed across communities. While the random coefficient model was fitted for household wealth (mean-centered), allowing to vary across communities. Finally, we adjusted both individual and community variables and a cross-level interaction between region and distance to the health facility to see any evidence of effect modification of the association between distance to health facility and PNC utilization by region.

The likelihood ratio test showed that the effect of wealth index variables significantly varied across communities indicating the random coefficient model provides a better fit than the random intercept model $(p=.005)$. Moreover, the model fit statistics, AIC, reduced as compared to intercept models indicating that allowing wealth index to vary across communities increased the predictive ability of the multilevel models for PNC. Moreover, we noticed that the intercept models do not provide additional information. As such, we reported random coefficient models.

Measures of associations were expressed as odds ratio (OR) and 95\% confidence interval (CI). Important assumptions and fitness of such statistical models were 
checked using the standard procedures. The goodnessof-fit of the models was assessed using the global Wald's statistics, the likelihood ratio test of the cluster-level random effects, and sensitivity of the quadrature approximation that was used to estimate the models.

\section{Results}

\section{Sociodemographic characteristics}

A total of 2724 women with live births in the 12 months preceding the survey were interviewed. Most of the respondents $(82.9 \%)$ were aged 34 years or below. The majority did not have any education $(58 \%)$ and about half of them lived within 30 min walking distance from a health post or health center (49.1\%). The majority of the respondents were Orthodox Christians (59.6\%), followed by Muslims (20.9\%), and then Protestant Christians (18.8\%). (Table 1).

\section{Obstetrics characteristics}

More than three-quarters of the women (77.1\%) had two or more children. Most (91.2\%) women attended ANC at least once during pregnancy, while about $52 \%$ continue to have at least four ANC consultations. A little less than two-thirds of mothers (66.1\%) delivered at health facility and about $5.6 \%$ of these delivered through cesarean sections. A little more than half of the mothers (55.1\%) mentioned at least three obstetric danger signs during pregnancy, childbirth, or postpartum. About 8.4\% of women encountered any obstetric complications during pregnancy, childbirth, or postpartum (Table 2).

\section{Health-service related factors}

A little less than one-third (31.8\%) of families were model families at the time of the survey; less than $10 \%$ of mothers had at least one family conversation during pregnancy. Likewise, about $41.1 \%$ of births were notified

Table 1 Background characteristics of women who had live birth in the 12 months preceding the survey in Ethiopia, 2017

\begin{tabular}{|c|c|c|}
\hline Background characteristics & Number of women (n) & Percentage (\%) \\
\hline \multicolumn{3}{|l|}{ Maternal age } \\
\hline$<20$ & 161 & 5.9 \\
\hline $20-34$ & 2098 & 77.0 \\
\hline $35-49$ & 465 & 17.1 \\
\hline \multicolumn{3}{|l|}{ Education } \\
\hline No education & 1571 & 57.7 \\
\hline Primary & 595 & 21.8 \\
\hline Higher & 558 & 20.5 \\
\hline \multicolumn{3}{|l|}{ Religion } \\
\hline Orthodox & 1623 & 59.6 \\
\hline Protestant & 512 & 18.8 \\
\hline Muslims & 568 & 20.9 \\
\hline Traditional/others & 21 & 0.8 \\
\hline \multicolumn{3}{|l|}{ Wealth quintile } \\
\hline Poorest & 545 & 20.0 \\
\hline Poorer & 546 & 20.0 \\
\hline Middle & 544 & 20.0 \\
\hline Richer & 551 & 20.2 \\
\hline Richest & 538 & 19.7 \\
\hline \multicolumn{3}{|c|}{ Walking distance to nearest health facility (health post or health center) } \\
\hline$<30 \min$ & 1337 & 49.1 \\
\hline$>=30 \mathrm{~min}$ & 1387 & 50.9 \\
\hline \multicolumn{3}{|l|}{ Region } \\
\hline Amhara & 929 & 34.1 \\
\hline Oromia & 713 & 26.2 \\
\hline SNNP & 687 & 25.2 \\
\hline Tigray & 395 & 14.5 \\
\hline Total & 2724 & 100.0 \\
\hline
\end{tabular}


Table 2 Distribution of women who had live birth within the last 12 months preceding the survey in Ethiopia, by obstetric characteristics, 2017

\begin{tabular}{|c|c|c|}
\hline Obstetric characteristics & Number of women $(n)$ & Percentage (\%) \\
\hline \multicolumn{3}{|l|}{ Number of children } \\
\hline 1 & 624 & 22.9 \\
\hline $2-3$ & 877 & 32.2 \\
\hline $4+$ & 1223 & 44.9 \\
\hline \multicolumn{3}{|c|}{ Mentioned at least 3 pregnancy danger signs } \\
\hline Yes & 883 & 32.4 \\
\hline No & 1841 & 67.6 \\
\hline \multicolumn{3}{|c|}{ Mentioned at least 3 childbirth danger signs } \\
\hline Yes & 1062 & 39.0 \\
\hline No & 1662 & 61.0 \\
\hline \multicolumn{3}{|c|}{ Mentioned at least 3 postpartum danger signs } \\
\hline Yes & 1180 & 43.3 \\
\hline No & 1544 & 56.7 \\
\hline \multicolumn{3}{|c|}{ Mentioned at least 3 pregnancy, intrapartum, or postpartum danger signs } \\
\hline Yes & 1501 & 55.1 \\
\hline No & 1223 & 44.9 \\
\hline \multicolumn{3}{|c|}{ Encountered complications during pregnancy } \\
\hline Yes & 208 & 7.7 \\
\hline No & 2515 & 92.3 \\
\hline \multicolumn{3}{|c|}{ Encountered complications during childbirth } \\
\hline Yes & 153 & 5.6 \\
\hline No & 2570 & 94.4 \\
\hline \multicolumn{3}{|c|}{ Encountered complications after childbirth } \\
\hline Yes & 107 & 3.9 \\
\hline No & 2616 & 96.1 \\
\hline \multicolumn{3}{|c|}{ Encountered complications during pregnancy, childbirth, or after childbirth } \\
\hline Yes & 228 & 8.4 \\
\hline No & 2495 & 91.6 \\
\hline \multicolumn{3}{|l|}{ Mode of delivery } \\
\hline Caesarean section delivery & 152 & 5.6 \\
\hline Vaginal delivery & 2572 & 94.4 \\
\hline Total & 2724 & 100.0 \\
\hline
\end{tabular}

to HEWs immediately after the mother delivered, either by the mother herself or anyone from her family or neighbor, for early PNC. Only a little higher than onethird $(36.9 \%)$ of women received home visits during pregnancy by CHWs (Table 3).

\section{Postnatal care service utilization}

Overall, about $36.8 \%$ (95\% CI: 35.0-38.6) of women received PNC service within 6 weeks after delivery-29.4\% (95\% CI: 27.7-31.1) of these received the service within $48 \mathrm{~h}$ and $34.1 \%$ (95\% CI: 32.3-35.8) within 7 days. About one-third (34\%) of the mothers received one PNC visit; only 2 and $1 \%$ received two and three PNC visits, respectively. Most of the mothers received PNC service at health facilities; $29 \%$ at the health facility and only $7 \%$ received at home. About a quarter (27\%) of mothers received PNC after birth in a health facility staying for at least 24-h.

\section{Factors associated with postnatal care utilization}

As presented in Table 4 below, Model 1, the intra-class correlation coefficient (ICC) showed that the community variance in PNC was estimated at $22 \%$. It means that $22 \%$ of the residual variation in the propensity to use 
Table 3 Percent distribution of women who had live birth within the last 12 months preceding the survey in Ethiopia, by healthservice related factors, 2017

\begin{tabular}{|c|c|c|}
\hline Health-service related factors & Number of women (n) & Percentage (\%) \\
\hline \multicolumn{3}{|c|}{ Antenatal care utilization (at least one) } \\
\hline At least one & 2481 & 91.2 \\
\hline None & 240 & 8.8 \\
\hline \multicolumn{3}{|l|}{ Antenatal care utilization (4+) } \\
\hline At least 4 visits & 1387 & 52.3 \\
\hline Less than 4 visits or none & 1266 & 47.7 \\
\hline \multicolumn{3}{|l|}{ Place of delivery } \\
\hline Facility & 1791 & 66.1 \\
\hline Home or elsewhere & 919 & 33.9 \\
\hline \multicolumn{3}{|c|}{ CHW (HEWs or WDAs) home visit during pregnancy } \\
\hline Yes & 1006 & 36.9 \\
\hline No & 1718 & 63.1 \\
\hline \multicolumn{3}{|l|}{ Used motorized transport for delivery } \\
\hline Yes & 1111 & 57.0 \\
\hline No & 838 & 43.0 \\
\hline \multicolumn{3}{|c|}{ Family currently recognized as model family } \\
\hline Yes & 867 & 31.8 \\
\hline No & 1857 & 68.2 \\
\hline \multicolumn{3}{|c|}{ Family conversations during pregnancy } \\
\hline Yes (at least 1) & 240 & 8.8 \\
\hline No & 2283 & 91.2 \\
\hline \multicolumn{3}{|l|}{ Birth notification } \\
\hline Yes & 1119 & 41.1 \\
\hline No & 1604 & 58.9 \\
\hline Total & 2724 & 100.0 \\
\hline
\end{tabular}

PNC services is attributable to unobserved community characteristics. The likelihood ratio test showed that there is strong evidence that the between community variance is non-zero (chi2 $=202.78 ; p<.01$ ).

Model 2 showed that PNC utilization was higher amongst mothers residing within 30 min walking distance from the nearest health facility (health post or health center) (AOR: 1.24; 95\% CI: 1.01-1.52). Women who mentioned at least 3 antepartum, intrapartum or postpartum danger signs had 30\% higher odds of receiving PNC (AOR: 1.30; 95\% CI: 1.05-1.60). The odds of receiving $\mathrm{PNC}$ was 10 times higher among those delivered at health facility (AOR: 10.29; 95\% CI: 7.57-13.98); more than 2 times higher among women whose birth was notified to HEWs (AOR: 2.66; 95\% CI: 2.15-3.29); and $96 \%$ higher among women who delivered through cesarean section (AOR: 1.96; 95\% CI: 1.28-3.00). Moreover, PNC utilization was higher amongst families recognized as model family (AOR: 1.27 ; 95\% CI: $1.03-$ 1.57 ) and those who had family conversation during pregnancy (AOR: 1.48; 95\% CI: 1.04-2.12), had higher odds of using PNC than their counterparts. However, the association between maternal education, wealth quintile, and PNC were not statistically significant.

Women who live in Oromia were 2.99 times higher odds of using PNC than those mothers who live in Amhara region (AOR: 2.99; 95\% CI: 2.07-4.32). However, the association between living in SNNP and Tigray region and $\mathrm{PNC}$ use were not statistically significant.

The cross-level interaction model, Model 3, revealed that there is evidence of effect modification of the association between distance to health facility and PNC utilization by region. Within the community effect of distance to the health facility, as well as within the community effect of the administrative region in Tigray disappears. In Tigray region, the odds of receiving PNC were significantly higher in those women who resided within 30 min walking distance to health facility as compared to women who resided further away from the facility (AOR: 2.28, 95\% CI 1.25-4.14). 
Table 4 Multilevel logistic regression results on the predictors of postnatal care in Ethiopia, 2017

\begin{tabular}{|c|c|c|c|}
\hline Characteristics & $\begin{array}{l}\text { Model } 1 \\
\text { Null model }\end{array}$ & $\begin{array}{l}\text { Model } 2 \\
\text { Coefficient model }\end{array}$ & $\begin{array}{l}\text { Model } 3 \\
\text { Interaction effects }\end{array}$ \\
\hline \multicolumn{4}{|l|}{ Maternal education } \\
\hline No education & & 1.00 & 1.00 \\
\hline Primary & & $0.95(0.74-1.21)$ & $0.94(0.73-1.21)$ \\
\hline Higher & & $0.97(0.75-1.26)$ & $0.97(0.74-1.26)$ \\
\hline \multicolumn{4}{|l|}{ Wealth quintile } \\
\hline Poorest & & 1.00 & 1.00 \\
\hline Poorer & & $0.88(0.63-1.23)$ & $0.87(0.62-1.22)$ \\
\hline Middle & & $0.83(0.59-1.216$ & $0.81(0.57-1.14)$ \\
\hline Richer & & $0.96(0.67-1.37)$ & $0.94(0.65-1.35)$ \\
\hline Richest & & $0.73(0.51-1.06)$ & $0.71(0.49-1.03)$ \\
\hline \multicolumn{4}{|l|}{ Distance to nearest health facility } \\
\hline$<30 \min$ & & $1.24(1.01-1.52)$ & $0.84(0.55-1.28)$ \\
\hline$>=30 \mathrm{~min}$ & & 1.00 & 1.00 \\
\hline \multicolumn{4}{|c|}{ Family recognized as model family } \\
\hline Yes & & $1.27(1.03-1.57)$ & $1.27(1.03-1.57)$ \\
\hline No & & 1.00 & 1.00 \\
\hline \multicolumn{4}{|c|}{ CHW home visit during pregnancy } \\
\hline Yes & & $1.98(1.58-2.50)$ & $1.98(1.57-2.50)$ \\
\hline No & & 1.00 & 1.00 \\
\hline \multicolumn{4}{|c|}{ At least one family conversations happened at home during pregnancy } \\
\hline Yes & & $1.48(1.04-2.12)$ & $1.49(1.04-2.13)$ \\
\hline No & & 1.00 & 1.00 \\
\hline \multicolumn{4}{|c|}{ Mentioned at least 3 antepartum, intrapartum, or postpartum danger signs } \\
\hline Yes & & $1.30(1.05-1.60)$ & $1.31(1.06-1.61)$ \\
\hline No & & 1.00 & 1.00 \\
\hline \multicolumn{4}{|c|}{ Encountered complications during pregnancy, childbirth, or after delivery } \\
\hline Yes & & $1.23(0.93-1.62)$ & $1.21(0.92-1.61)$ \\
\hline No & & 1.00 & 1.00 \\
\hline \multicolumn{4}{|l|}{ Birth notification } \\
\hline Yes & & $2.66(2.15-3.29)$ & $2.69(2.17-3.34)$ \\
\hline No & & 1.00 & 1.00 \\
\hline \multicolumn{4}{|l|}{ Antenatal care utilization } \\
\hline At least 4 visits & & $1.04(0.84-1.28)$ & $1.03(0.83-1.28)$ \\
\hline Less than 4 visits or none & & 1.00 & 1.00 \\
\hline \multicolumn{4}{|l|}{ Place of delivery } \\
\hline Facility & & $10.29(7.57-13.98)$ & $10.47(7.69-14.26)$ \\
\hline Home or elsewhere & & 1.00 & 1.00 \\
\hline \multicolumn{4}{|l|}{ Mode of delivery } \\
\hline Vaginal delivery & & 1.00 & 1.00 \\
\hline Cesarean section delivery & & $1.96(1.28-3.00)$ & $2.00(1.30-3.05)$ \\
\hline \multicolumn{4}{|l|}{ Community characteristics } \\
\hline \multicolumn{4}{|l|}{ Region } \\
\hline Amhara & & 1.00 & 1.00 \\
\hline
\end{tabular}


Table 4 Multilevel logistic regression results on the predictors of postnatal care in Ethiopia, 2017 (Continued)

\begin{tabular}{|c|c|c|c|}
\hline Characteristics & $\begin{array}{l}\text { Model } 1 \\
\text { Null model }\end{array}$ & $\begin{array}{l}\text { Model } 2 \\
\text { Coefficient model }\end{array}$ & $\begin{array}{l}\text { Model } 3 \\
\text { Interaction effects }\end{array}$ \\
\hline Oromia & & $2.99(2.07-4.32)$ & $2.51(1.55-4.06)$ \\
\hline SNNP & & $1.34(0.93-1.94)$ & $1.06(0.66-1.72)$ \\
\hline Tigray & & $1.30(0.87-1.93)$ & $0.85(0.51-1.41)$ \\
\hline \multicolumn{4}{|l|}{ Distance to health facility* Region } \\
\hline$<30 \mathrm{~min}^{*}$ Oromia & & & $1.37(0.77-2.45)$ \\
\hline$<30 \mathrm{~min}^{*} \mathrm{SNNP}$ & & & $1.53(0.86-2.72)$ \\
\hline$<30$ min*Tigray & & & $2.28(1.25-4.14)$ \\
\hline Community level intercepts (SE) & $* 0.66(0.05)$ & ${ }^{*} 0.02(0.01)$ & ${ }^{*} 0.03(0.01)$ \\
\hline \multicolumn{4}{|l|}{ Random effects } \\
\hline Coefficient variance (SE) & - & ${ }^{*} 0.03(0.02)$ & ${ }^{*} 0.03(0.02)$ \\
\hline Community level variance (SE) & $* 0.91(0.14)$ & $* 0.46(0.11)$ & $* 0.48(0.11)$ \\
\hline Covariance (SE) & - & $*_{-0.12(0.04)}$ & $*_{-0.13(0.04)}$ \\
\hline Log-likelihood & 202.78 & 60.09 & 62.83 \\
\hline \multicolumn{4}{|l|}{ Model fit statistics } \\
\hline ICC (SE) & $0.22(0.03)$ & $0.12(0.02)$ & $0.13(0.03)$ \\
\hline AlC & 3494.46 & 2761.47 & 2759.93 \\
\hline
\end{tabular}

\section{Discussion}

Region of residence, obstetric, and service-related factors are the major determinants for the use of PNC among rural women in Ethiopia.

The cross-interaction model showed that region modified the association between distance to facility and PNC. The association between proximity of women to health care facilities and uptake of PNC significantly varied across regions. Women who resided near facilities in Tigray region were significantly receiving PNC as compared to communities who live far from the facility. This suggests the existence of differential geographic access to PNC, despite the program being pro-poor, as documented in this study and other studies in Ethiopia [25]. Mothers in Tigray region have better access to health facility and receiving PNC or mothers who lived near a facility in Tigray might be motivated to visit health facilities and receive services or HEWs are motivated to visit them at home disproportionally. Previous studies in developing countries also suggest that where health services are brought closer to the people, it could improve the uptake of the services including PNC $[19,26]$. As such, it underlines the need for expansion of health facilities or designs appropriate strategies to reach the disadvantaged communities.

Illness-level factors such as knowledge of obstetric danger signs and delivery through cesarean section are determining the use of PNC service. Mothers who delivered through cesarean section were more likely to receive PNC services than mothers who delivered through spontaneous vaginal delivery. As documented in this study, about $73 \%$ of the women who received PNC at a health facility, stayed there after delivery. Mothers likely received PNC before discharge, would be delivered by cesarean section. Previous studies in rural Ethiopia [1214] also showed women who had cesarean births used more postpartum care than those who had vaginal births. The result of this study revealed that the use of PNC services has been significantly influenced by knowledge of antepartum, intrapartum, or postpartum danger signs This is in line with the studies carried out in Ethiopia [13, 14]. An integrative review by Adams and Smith suggested that awareness about pregnancy, childbirth, and/or postpartum complications is one of the common determinants of postpartum care use in developing countries [27].

The service-related factors-family conversation; CHWs' home visit during pregnancy; and HEWs being notified of the birth, were predicting factors for the use of PNC. Participating in at least one family conversation during pregnancy was associated with the use of PNC services. The effect of family conversation on early PNC visits was also documented in earlier studies in Ethiopia $[28,29]$. A similar study suggests that family conversations could potentially play a crucial role in changing a family's behaviors towards better maternal and newborn care practices through dismantling family healthcare decision-making barriers discussing birth preparedness and essential newborn practices with family members together [28]. Another intervention study on communitybased collaborative approach involving HEWs and community health development agents illustrates that 
having two to four community maternal and newborn health family meetings during pregnancy with a family member was associated with the receipt of PNC [29]. Likewise, mothers/relatives/WDAs who informed HEWs about the birth immediately after delivery were about 2 times more likely to use PNC than their counterparts. This is in agreement with a previous observational study of a collaborative community-based quality improvement intervention in Ethiopia which involved family meetings and labor and birth notification contributed to the increased receipt of PNC within $48 \mathrm{~h}$ by skilled providers or HEWs [30]. This notification system might motivate HEWs to do home visits for the provision of PNC to the mother and the newborn.

Being recognized as a model family was associated with the uptake of PNC. This shows the contribution of the HEP in mobilizing the community and HEWs efforts of educating families on uptake of PNC. Model families are early adopters of the HEP education and package of services as well as role models to their communities. Their knowledge, skills, and behavior change in health practices they gained and their models in their community would influence the uptake of PNC [20]. Previous studies in Ethiopia also demonstrate that model family was more likely to use the HEP [31] and maternal health services [32].

Community health workers' home visits during pregnancy where they discussed health-related issues, were statistically significantly linked with the use of PNC. A study in Tanzania also showed that counseling by a CHW to go to a facility for PNC was associated with PNC utilization [33]. Other studies in Ethiopia demonstrate that women who receive information about PNC services, utilize PNC [25]. A randomized trial by McConnell et al. [34] in Kenya found that CHWadministered postnatal checklists lead to better recognition of postnatal problems and more likely to seek care.

Antenatal care visits and institutional delivery would have a positive impact on the utilization of postpartum healthcare services if adequate counseling was provided regarding the need to seek PNC and avoid possible postpartum complications $[9,19,26]$. The odds of receiving PNC is higher among women who delivered in health facility. This might be due to mothers were advised about the need to have a follow-up visit before being discharged from health facility after delivery or birth notification after delivery to HEWs to do PNC home visits as documented in this study. However, like other studies elsewhere [35], this study shows that antenatal consultations were not associated with uptake of PNC which might be because mothers were not likely informed about the importance of PNC; its availability; recommended timing; and targeted frequency of postnatal visits, during their antenatal visits and before being discharged from health facility after delivery. These were documented by previous studies [35, 36]. This suggests that not enough emphasis is being given to the importance of PNC during antepartum contact, which is a missed opportunity for the health system to increase uptake of PNC.

Common demographic characteristics including maternal age, maternal education, and household wealth did not determine the utilization of PNC. Though this finding is congruent with the national pro-poor health policies and strategies, there is no concluding evidence in the global literature that these characteristics are determining the use of PNC. Some studies in Ethiopia [14, 25] and elsewhere [33] showed that demographic characteristics like marital status, maternal age, education, ethnicity, income, prior obstetric history, and cultural practices, did not have a significant association with the utilization of PNC. A recent systematic review of studies in Ethiopia also showed that maternal education did not have a significant association with the use of PNC [9]. This might have related to the PNC service delivery strategy. One thing maternal health services in Ethiopia are provided free of charge and another thing is as most of the women receiving PNC associated with their delivery, pre-discharge care, and home-based PNC.

Applying advanced analytic techniques, multilevel cluster-level random effect models, we estimated the effects of contextual variables and their interactions with individual-level variables on the use of PNC in Ethiopia which is critical to developing effective strategies to improve the delivery of PNC in the country. Despite the efforts to minimize biases using memory aids, pretested the survey tools, trained data collectors, and allocated adequate days for the primary data collection, the findings of this study may have been affected by social desirability and recall biases.

\section{Conclusions}

In conclusion, this study identified multiple factors- obstetric, health service-related, and region of residence that influence PNC utilization in rural Ethiopia. Efforts to improve PNC coverage must consider a comprehensive intervention package that promotes utilization of services at the community and facility levels.

Exploring women's perspectives on PNC service in general and the acceptability and feasibility of keeping women and newborns for at least $24 \mathrm{~h}$ at health facilities for postpartum observation, in particular, would be helpful.

\section{Supplementary information}

Supplementary information accompanies this paper at https://doi.org/10. 1186/s12884-020-03254-7.

Additional file 1:. Survey Questionnaire.doc. Survey questionnaire we used to collect information from respondents. 


\section{Abbreviations}

ANC: Antenatal care; CBDDM: Community-based data for decision making; CHW: Community health worker; Cl: Confidence interval; EDHS: Ethiopian demographic and health survey; HEP: Health extension program; HEW: Health Extension Worker; ICC: Intra-class correlation coefficient; L10K: Last Ten Kilometers Project; OR: Odds ratio; PNC: Postnatal care; RMNC $\mathrm{H}$ : Reproductive, maternal, newborn and child health; SNNP: Southern Nations, Nationalities, and Peoples'; WDA: Women's development army

\section{Acknowledgments}

Addis Continental Institute of Public Health (ACIPH) and University of Gondar (UoG) are acknowledged for providing support during analysis and write up. I would also like to take this opportunity to acknowledge JSI Research and Training Institute Inc. /The Last Ten Kilometers Project, for allowing us to use the data for this paper. We would also like to acknowledge our colleagues at The Last Ten Kilometers Project of JSI Research and Training Institute Inc. for their contributions at all stages of implementing the research.

\section{Authors' contributions}

GT and WB: conceived the study design and methods. GT, AW, YB, and MD: formulate the research question, analysis method, interpretation, and critical review. GT: drafted the manuscript. WB: received the grant, interpretation, and critical review. All authors read and approved the final manuscript.

\section{Funding}

The authors declare that they did not receive funding for this research from any source.

\section{Availability of data and materials}

The raw data used for this study is available upon reasonable request from the corresponding author.

\section{Ethics approval and consent to participate}

In this study, we report findings from a secondary analysis of the data collected by JSI Research and Training Institute Inc. /The Last Ten Kilometers Project, in which GT and WB are part of the research team. Ethical clearance for the study was provided by ethical review boards of Amhara, Oromia, SNNP, and Tigray Regional Health Bureaus, and JSI. Verbal consents from respondents were sought and documented by interviewers before interviewing. Voluntary participation was ensured during interviews [23]. For this study, we obtained permission to use the data from the JSI, and ethics approval was obtained from the Research and Ethics Committee of the Department of Health Studies of the University of Gondar (reference number V/P/RCS/05/2505/2019; dated on 25 August 2019).

\section{Consent for publication}

Not applicable.

\section{Competing interests}

The authors declare that they have no competing interests.

\section{Author details}

'The Last Ten Kilometers (L1OK) Project, JSI Research \& Training Institute, Inc, Addis Ababa, Ethiopia. ${ }^{2}$ Addis Ababa University School of Public Health, Addis Ababa, Ethiopia. ${ }^{3}$ Addis Continental Institute of Public Health, Addis Ababa, Ethiopia.

Received: 11 June 2020 Accepted: 15 September 2020

Published online: 21 September 2020

\section{References}

1. Lawn JE, Kerber K, Enweronu-Laryea C, Cousens S. 3.6 million neonatal deaths-what is progressing and what is not? Semin Perinatol. 2010;34(6): 371-86.

2. Lawn JE, Blencowe H, Waiswa P, Amouzou A, Mathers C, Hogan D, et al. Stillbirths: rates, risk factors, and acceleration towards 2030. Lancet. 2016; 387(10018):587-603. https://doi.org/10.1016/S0140-6736(15)00837-5.

3. Kerber KJ, de Graft-Johnson JE, Bhutta ZA, Okong P, Starrs A, Lawn JE. Continuum of care for maternal, newborn, and child health: from slogan to service delivery. Lancet. 2007;370(9595):1358-69.
4. MoH. Implementation Guide for -24hours postnatal care and stay. Addis Ababa, Ethiopia: Minstry of Health, Ethiopia; 2018.

5. Central Statistical Agency (CSA) [Ethiopia], ICF. Ethiopia Demographic and Health Survey 2016. Addis Ababa, Ethiopia, and Rockville, Maryland, USA: CSA and ICF; 2016.

6. Kaba M, Taye G, Gizaw M, Mitiku I. Maternal health service utilization in urban slums of selected towns in Ethiopia: qualitative study. Ethiop J Health Dev. 2017;31(2):96-102.

7. Darega B, Dida N, Tafese F, Ololo S. Institutional delivery and postnatal care services utilizations in Abuna Gindeberet District, west Shewa, Oromiya region, Central Ethiopia: a community-based cross sectional study. BMC Pregnancy Childbirth. 2016;16(1):149.

8. Agunwa CC, Obi IE, Ndu AC, Omotowo IB, Idoko CA, Umeobieri AK, et al. Determinants of patterns of maternal and child health service utilization in a rural community in south eastern Nigeria. BMC Health Serv Res. 2017; 17(1):715. https://doi.org/10.1186/s12913-017-2653-x.

9. Chaka EE, Abdurahman AA, Nedjat S, Majdzadeh R. Utilization and determinants of postnatal Care Services in Ethiopia: a systematic review and meta-analysis. Ethiop J Health Sci. 2019;29(1):935-44. https://doi.org/10. 4314/ejhs.v29i1.16.

10. Singh K, Brodish P, Chowdhury ME, Biswas TK, Kim ET, Godwin C, et al. Postnatal care for newborns in Bangladesh: the importance of healthrelated factors and location. J Glob Health. 2017;7(2):020507. https://doi.org/ 10.7189/jogh.07.020507.

11. Worku AG, Yalew AW, Afework MF. Factors affecting utilization of skilled maternal care in Northwest Ethiopia: a multilevel analysis. BMC Int Health Hum Rights. 2013;13(1):20. https://doi.org/10.1186/1472-698X-13-20.

12. Mehari $\mathrm{K}$, Wencheko $\mathrm{E}$. Factors affecting maternal health care services utilization in rural Ethiopia: a study based on the 2011 EDHS data. Ethiop J Health Dev. 2013;27(1):16-24.

13. Limenih MA, Endale ZM, Dachew BA. Postnatal care service utilization and associated factors among women who gave birth in the last 12 months prior to the study in Debre Markos town, northwestern Ethiopia: a community-based cross-sectional study. Int J Reprod Med. 2016;2016: 7095352.

14. Berhe A, Bayray A, Berhe Y, Teklu A, Desta A, Araya T, et al. Determinants of postnatal care utilization in Tigray, northern Ethiopia: a community based cross-sectional study. PLoS One. 2019;14(8):e0221161.

15. Tesfahun F, Worku W, Mazengiya F, Kifle M. Knowledge, perception and utilization of postnatal Care of Mothers in Gondar Zuria District, Ethiopia: a cross-sectional study. Matern Child Health J. 2014;18(10):2341-51. https:// doi.org/10.1007/s10995-014-1474-3.

16. Wang W, Hong R. Levels and determinants of continuum of care for maternal and newborn health in Cambodia-evidence from a populationbased survey. BMC Pregnancy Childbirth. 2015;15(1):62. https://doi.org/10, 1186/s12884-015-0497-0.

17. Degefie T, Amare Y, Mulligan B. Local understandings of care during delivery and postnatal period to inform home based package of newborn care interventions in rural Ethiopia: a qualitative study. BMC Int Health Hum Rights. 2014;14(1):17. https://doi.org/10.1186/1472-698X14-17.

18. WHO. WHO recommendations on postnatal care of the mother and newborn. Geneva, Switzerland: World health Organization; 2014.

19. Ononokpono DN, Odimegwu CO, Imasiku ENS, Adedini SA. Does it really matter where women live? A multilevel analysis of the determinants of postnatal Care in Nigeria. Matern Child Health J. 2014;18(4):950-9. https:// doi.org/10.1007/s10995-013-1323-9.

20. MOH. Ethiopia Health Sector Transformation Plan (2015/16-2019/2020). Addis Ababa, Ethiopia: Ministry of health, Ethiopia; 2015.

21. Karim AM, Fesseha Zemichael N, Shigute T, Emaway Altaye D, Dagnew S, Solomon $F$, et al. Effects of a community-based data for decision-making intervention on maternal and newborn health care practices in Ethiopia: a dose-response study. BMC Pregnancy Childbirth. 2018;18(1):359. https://doi. org/10.1186/s12884-018-1976-X.

22. L10K. Maternal and newborn health care behaviours and practices in 115 L10K districts: Baseline and follow-up surveys 2016-2017. Addis Ababa, Ethiopia: JSI Research and Training Institute Inc./The Last Ten Kilometers (L10K) Project; 2018.

23. Tiruneh GT, Zemichael NF, Betemariam WA, Karim AM. Effectiveness of participatory community solutions strategy on improving household and provider health care behaviors and practices: a mixed-method evaluation. 
PLoS One. 2020;15(2):e0228137. https://doi.org/10.1371/journal.pone. 0228137.

24. Andersen RM. Revisiting the behavioral model and access to medical care: does it matter? J Health Soc Behav. 1995:36:1-10.

25. Angore BN, Tufa EG, Bisetegen FS. Determinants of postnatal care utilization in urban community among women in Debre Birhan town, northern Shewa, Ethiopia. J Health Popul Nutr. 2018;37(1):10. https://doi.org/10.1186/ s41043-018-0140-6.

26. Sakeah E, Aborigo R, Sakeah JK, Dalaba M, Kanyomse E, Azongo D, et al. The role of community-based health services in influencing postnatal care visits in the Builsa and the west Mamprusi districts in rural Ghana. BMC Pregnancy Childbirth. 2018;18(1):295. https://doi.org/10.1186/s12884-0181926-7.

27. Adams YJ, Smith BA. Integrative review of factors that affect the use of postpartum care services in developing countries. J Obstet Gynecol Neonatal Nurs. 2018;47(3):371-84.

28. Altaye DE, Karim AM, Betemariam W, Zemichael NF, Shigute T, Scheelbeek P. Effects of family conversation on health care practices in Ethiopia: a propensity score matched analysis. BMC Pregnancy Childbirth. 2018;18(1): 372.

29. Barry D, Frew AH, Mohammed H, Desta BF, Tadesse L, Aklilu Y, et al. The effect of community maternal and newborn health family meetings on type of birth attendant and completeness of maternal and newborn care received during birth and the early postnatal period in rural Ethiopia. J Midwifery Women's Health. 2014;59(s1):S44-54.

30. Tesfaye S, Barry D, Gobezayehu AG, Frew AH, Stover KE, Tessema H, et al. Improving coverage of postnatal Care in Rural Ethiopia Using a Communitybased, collaborative quality improvement approach. J Midwifery Women's Health. 2014;59(s1):S55-64. https://doi.org/10.1111/jmwh.12168.

31. Yitayal M, Berhane $\mathrm{Y}$, Worku A, Kebede $\mathrm{Y}$. Health extension program factors, frequency of household visits and being model households, improved utilization of basic health services in Ethiopia. BMC Health Serv Res. 2014; 14(1):156. https://doi.org/10.1186/1472-6963-14-156.

32. Medhanyie A, Spigt M, Kifle Y, Schaay N, Sanders D, Blanco R, et al. The role of health extension workers in improving utilization of maternal health services in rural areas in Ethiopia: a cross sectional study. BMC Health Serv Res. 2012;12(1):352. https://doi.org/10.1186/1472-6963-12-352.

33. Mohan D, LeFevre AE, George A, Mpembeni R, Bazant E, Rusibamayila N, et al. Analysis of dropout across the continuum of maternal health care in Tanzania: findings from a cross-sectional household survey. Health Policy Plan. 2017;32(6):791-9. https://doi.org/10.1093/heapol/czx005.

34. McConnell M, Ettenger A, Rothschild CW, Muigai F, Cohen J. Can a community health worker administered postnatal checklist increase healthseeking behaviors and knowledge?: evidence from a randomized trial with a private maternity facility in Kiambu County, Kenya. BMC Pregnancy Childbirth. 2016;16(1):136. https://doi.org/10.1186/s12884-016-0914-z.

35. Mon A, Phyu M, Thinkhamrop W, Thinkhamrop B. Utilization of full postnatal care services among rural Myanmar women and its determinants: a crosssectional study [version 1; referees: 3 approved]. F1000Research. 2018;7: 1167. https://doi.org/10.12688/f1000research.15561.1.

36. Izudi J, Amongin D. Use of early postnatal care among postpartum women in eastern Uganda. Int J Gynecol Obstet. 2015;129(2):161-4. https://doi.org/ 10.1016/j.ijgo.2014.11.017.

\section{Publisher's Note}

Springer Nature remains neutral with regard to jurisdictional claims in published maps and institutional affiliations.

Ready to submit your research? Choose BMC and benefit from:
- fast, convenient online submission
- thorough peer review by experienced researchers in your field
- rapid publication on acceptance
- support for research data, including large and complex data types
- gold Open Access which fosters wider collaboration and increased citations
- maximum visibility for your research: over 100M website views per year
At BMC, research is always in progress.
Learn more biomedcentral.com/submissions

